* Lara Caxico Martins, Graduanda do $4^{\circ}$ ano de Direito da Universidade Estadual de Londrina, bolsista CNPq, Participante do projeto de pesquisa Diálogos Jurídicos e Filosóficos: parâmetros ecocêntricos do constitucionalismo latinoamericano e do documento "o futuro que nós queremos" para os negócios públicos e empresariais.

E-mail:

laracaxico@hotmail.com

** Marlene Kempfer, Possui graduação em Direito pela Faculdade de Direito de Curitiba (1981), mestrado em Direito pela Pontifícia Universidade Católica de São Paulo (1995) e doutorado em Direito pela Pontifícia Universidade Católica de São Paulo (2002). Atualmente é professora ADJ-D na Universidade Estadual de Londrina, atuando na graduação, especialização e no Mestrado em Direito Negocial. É professora titular da Universidade de Marília-SP na graduação e mestrado. Professora titular da Pontifícia Universidade Católica do Paraná -Campus Londrina. E-mail: rdpubuel@uel.br

\section{Trabalho escravo urbano contemporâneo: 0 trabalho de bolivianos nas oficinas de costura em São Paulo}

\author{
CONTEMPORARY URBAN SLAVE LABOR: \\ BOLIVIANS WORK IN SEWING WORKSHOPS OF \\ São Paulo
}

Lara Caxico Martins * Marlene Kempfer **

Resumo: A Constituição Federal Brasileira de 1988 prevê, em seu Art. $1^{\circ}$, III, entre seus fundamentos a dignidade da pessoa humana. Mas, infelizmente, hoje no Brasil há inúmeros casos de cidadãos bolivianos reduzidos à condição análoga a de escravo também no campo das oficinas de costura na grande São Paulo. A fiscalização do Ministério do Trabalho e relatórios da OIT denunciam que diversos trabalhadores são submetidos a baixíssimos salários, locais insalubres de trabalho, péssimas condições de higiene e moradia. Estas condições são afronta ao conceito de trabalho decente previsto como direito pela legislação trabalhista brasileira, Convenção 29 da OIT, em seu Art. $2^{\circ}$ (1930), função social da propriedade empresarial (Art. 170, III $\mathrm{CF} / 88$ ) e à definição de crime (Artigo $149 \mathrm{CPP}$ ). O escravagista é aquele que rouba não somente a liberdade mas, também, a dignidade humana e não deve ficar impune. Em face desta realidade e para enfrenta-la está em trâmite a Proposta de Emenda Constitucional $n^{\circ} 438 / 01$ (que volta a tramitar como PEC 57A/1999), que propõe alterar o artigo 243 da CF/88 e prevê como sanção a expropriação de imóveis rurais e urbanos. O Brasil vê-se diante da possibilidade da abolição de novas formas de escravatura e da possibilidade de garantir a esses cidadãos os direitos dos trabalhadores que lhes são devidos.

Palavras-chave: Escravidão. Bolivianos. Trabalho escravo urbano. Trabalho decente.

Abstract: The Brazilian Constitution of 1988 provides, in its Article1, III, from its foundations to human dignity. But, unfortunately, today in Brazil there are numerous cases of Bolivian citizens reduced to a condition analogous to sla very also in the field of sewing workshops in greater São Paulo. The supervision of the Ministry of Labour and OIT reports complain that many workers are subjected to very low wages, unhealthyplacesofwork, poorhygieneandhousing. These 
conditions are an affront to the concept of decent work as a right provided by Brazilian labor legislation, OIT Convention No. 29, in its Article2 (1930), corporate social function of property (Art. 170, III, CF/88) and the definition of crime (Article 149 CPP). The slave holder so new hoste als, not only freedom, but also human dignity and must not go unpunished. In the face of this reality and facing, it is pending the Proposed Constitutional Amendment $n^{\circ} 438 / 01$ (which returns to transact as $57 \mathrm{~A} / 1999$ PEC), which proposes to amend Article 243 of $\mathrm{CF} / 88$ and provides as a sanction expropriation of rural and urban properties. Brazil see it self facing the possibility of new form sof the abolition of sla very and the possibility to guarantee the se people the rights of workers dueto them.

Keywords: Slavery. Bolivians. Urbans lave labor. Decente work. 


\section{INTRODUÇÃO}

Nos últimos anos mudanças políticas e sociais significativas foram verificadas nos países da América Latina. A ascensão de governos de opção política com ênfase em direitos sociais e transindividuais proporcionam, ao menos, vislumbres de Estados mais humanistas e protecionistas dos direitos laborais.

Propostas de desenvolvimento sustentável com novos conceitos sobre bem-estar se tornaram temas de importantes acontecimentos na América Latina, em destaque a recente Conferência Rio+20 (2013) e a aprovação de novas Constituições como a brasileira (1988), a Venezuelana (1999), Boliviana (2007) e a mais recente equatoriana (2008).

Os novos governos latinos têm desafios diante da dívida histórica de grupos excluídos e vulneráveis e precisam atuar no combate de tais desigualdades. O primeiro importante passo é registrar, em nível constitucional, políticas de Estado para orientar os governos que sucessivamente programam as suas políticas de inclusão. Os desafios são muitos tendo em vista que a maioria dos países da América do Sul tem os menores índices de desenvolvimento humano (IDH) levantados pela ONU, ficando a frente da África.

No caso da Bolívia, entre os valores constitucionais nos quais o atual Estado se sustenta aponta,entre outras formas, a equidade social para alcançar uma sociedade socialmente igualitária. Esta prioridade é essencial em face da dura realidade de possuir um dos menores IDH da América do Sul. Está acima apenas da Guiana, segundo o Ranking apresentado pelo PNDU (PROGRAMA DAS NAÇÕES UNIDAS PELO DESENVOLVIMENTO, 2012).

Estes dados quando cotejados, por exemplo, com os do Brasil que está na posição 85, por certo, pode ser apontado como uma das causas do processo imigratório que está ocorrendo com trabalhadores bolivianos em direção a São Paulo (capital), para trabalhar no ramo da confecção de roupas, em buscas de melhores condições de vida e trabalho.

Mais do que uma questão puramente econômica e de ascensão social, o elevado índice imigratório evidencia uma questão de decepção com as condições de vida em especial apouca efetividade dos direitos sociais previstos no sistema jurídico boliviano. Infelizmente, ao chegarem ao Brasil a decepção continua, pois aqui as condições de trabalho que lhe foram ofertadas caracterizam o uso de mão de obra análoga á condição de escravos.

A indústria têxtil brasileira, para enfrentar planos econômicos governamentais de abertura da economia e da concorrência internacional, 
especialmente, por volta de 1980, atraiu a mão de obra barata dos imigrantes bolivianos sem lhes proporcionar acesso aos direitos e garantias do sistema jurídico brasileiro. Estes trabalhadores se deslocavam e se deslocam da Bolívia e encontram no Brasil condições não muito diferentes do seu país.

Esta realidade precisa ser enfrentada tanto em nível nacional brasileiro quanto boliviano e da América Latina, uma vez que nos termos das recentes constituições do Brasil e da Bolívia os governos devem ter como princípio, em suas relações internacionais, a integração econômica, política, social e cultural dos povos da América Latina:

Art. $4^{\circ}$, parágrafo único. A República Federativa do Brasil buscará a integração econômica, política, social e cultural dos povos da América Latina, visando à formação de uma comunidade latino-americana de nações. (Constituição Federal da República Federativa do Brasil, 1988).

Artículo 264, I. El Estado promoverá, sobre losprincipios de una relación justa, equitativa y conreconocimiento de lasasimetrías, las relaciones de integración social, política, cultural y económica conlosdemás Estados, naciones y pueblosdel mundo; en particular, promoverá laintegraciónlatinoamericana. (BOLIVIA, 2007).

\section{TRABALHO DECENTE}

Para que se comprove a convivência atual com a escravidão, necessário se faz definir o que vem a ser a escravidão contemporânea. Esta possui, sem hesitação, limiares que a difere da escravidão abolida no Brasil, no plano jurídico, pela Lei Áurea. Para definir escravidão moderna é importante buscar o atual conceito de trabalho decente tanto no âmbito interno quanto internacional.

Segundo a Organização Internacional do Trabalho (OIT) o Trabalho Decente é a reunião, concretização e alcance dos objetivos estratégicos da OIT. Estes, formulados em 1999, são: o respeito aos direitos no trabalho, a promoção do emprego produtivo e de qualidade, a extensão da proteção social e o fortalecimento do diálogo social. A OIT relembra ainda que são direitos no trabalho aqueles estabelecidos como fundamentais pela Declaração Relativa aos Direitos e Princípios Fundamentais no Trabalho, quais sejam,a liberdade sindical e reconhecimento efetivo do direito de negociação coletiva; a eliminação de todas as formas de trabalho forçado; a abolição efetiva do trabalho infantil e 
a eliminação de todas as formas de discriminação em matéria de emprego e ocupação. (ORGANIZAÇÃO INTERNACIONAL DO TRABALHO, 2013).

Em vistas de alcançar aplicabilidade do Trabalho Decente no Brasil, em 2006 foi lançada, em Brasília-DF, pelo Ministério do Trabalho e do emprego, a Agenda Nacional de Trabalho Decente. Esta rememorou o conceito abordado pela OIT e definiu para aplicação perante o ordenamento jurídico brasileiro o trabalho decente como sendo

[...] uma condição fundamental para a superação da pobreza, a redução das desigualdades sociais, a garantia da governabilidade democrática e o desenvolvimento sustentável. Entende-se por Trabalho Decente um trabalho adequadamente remunerado, exercido em condições de liberdade, eqüidade e segurança, capaz de garantir uma vida digna. (AGENDA, 2006, p. 5)

$\mathrm{Na}$ esteira desse conhecimento define José Claudio Monteiro de Brito Filho (2004, p. 61):

Trabalho Decente é um conjunto mínimo de direitos do trabalhador que corresponde: à existência de trabalho; à liberdade de trabalho; à igualdade no trabalho; ao trabalho com condições justas, incluindo a remuneração, e que preservem sua saúde e segurança; à proibição do trabalho infantil; à liberdade sindical; e à proteção contra os riscos sociais.

A partir dos conceitos abordados destaca-se que trabalho decente é aquele que garante não apenas o mínimo existencial para a sobrevivência do trabalhador e de sua família, mas, principalmente, aquele que lhe permite qualidade de vida. Há muito não se fala da necessidade apenas de trabalho, no entanto, tal visão foi superada por uma concepção de que é possível trabalho que concilie com a racionalidade de uma econômica mais humanitária.

Para tanto se defende a necessidade de efetivação de políticas públicas (Estado) e empresariais (mercado) que garantam ao indivíduo um trabalho digno, ou seja, produtivo e com uma remuneração equitativa, com segurança no local de trabalho e proteção para as famílias, com meio ambiente material e imaterial sadios, com liberdade de expressão e igualdade de oportunidades para homens e mulheres.

Nestes termos se manifesta José Claudio Monteiro de Brito Filho: não há trabalho decente sem condições adequadas à preservação da vida e da saúde do trabalhador. Não há trabalho decente sem justas condições para o 
trabalho, principalmente no que toca às horas de trabalho e aos períodos de repouso. Não há trabalho decente sem justa remuneração pelo esforço despendido. Não há trabalho decente se o Estado não toma todas as medidas necessárias para a criação e para a manutenção dos postos de trabalho. Não há, por fim, trabalho decente se o trabalhador não está protegido dos riscos sociais, parte deles originada do próprio trabalho humano (BRITO FILHO, 2004, p.61).

Esta interpretação está conforme o compromisso do Estado brasileiro com nacionais e estrangeiros nos seguintes termos do Art. $5^{\circ}$ da $\mathrm{CF} / 88$, ao tratar dos direitos fundamentais individuais e coletivos: "Todos são iguais perante a lei, sem distinção de qualquer natureza, garantindo-se aos brasileiros e aos estrangeiros residentes no País a inviolabilidade do direito à vida, à liberdade, à igualdade, à segurança e à propriedade, nos termos seguintes..."; bem como dos direitos sociais no Art. $7^{\circ}$ : "São direitos dos trabalhadores urbanos e rurais, além de outros que visem à melhoria de sua condição social [:..]".

Portanto, os parâmetros jurídicos brasileiros para avaliar a condição decente do trabalho humano estão positivados sendo possível julgar em que condições um ser humano poderá ser considerado trabalhador em condições inaceitáveis de trabalho escravo.

\section{O TRABALHO ESCRAVO CONTEMPORÂNEO}

Para o âmbito jurídico brasileiro a escravidão já foi extinta, mas, a realidade permite constatar que ainda no Brasil e em vários países, especialmente, os subdesenvolvidos e os em desenvolvimento diversos trabalhadores são encontrados em condições análogas a de escravos. A antiga compra e venda de pessoas foi substituída por uma escravidão moderna que, de modo semelhante, oprime e molesta os trabalhadores.

Sobre o tema se posiciona a autora Lívia Mendes Moreira Miraglia (2008, p. 134):

Ainda que tal situação seja vedada pelo ordenamento jurídico brasileiro, encontrando-se seus proibitivos em diversos artigos da Carta Magna (ver arts. $1^{\circ}$, caput, e incisos III e IV; $3^{\circ} ; 4^{\circ} ; 5^{\circ}$, caput, e incisos III, X, XIII, XV, LXVII e parágrafo $2^{\circ} ; 170$ ) e em inúmeros tratados e convenções internacionais (Ex: Convenções 29, ratificada em 1930, e 105, ratificada em 1957, ambas da OIT), sendo tipificada como crime pelo art. 149 do Código Penal, empregadores 
obstinados pelo lucro insistem em dar sobrevida à prática do trabalho escravo no país.

Faz-se fundamental estudar o conceito de trabalho escravo contemporâneo uma vez que as práticas escravagistas remontam às civilizações antigas e esta conduta se manifestava das mais diferentes formas ao longo dos séculos, mas,têm em comum a exploração econômica para obter vantagem usando o trabalho, sem um mínimo de equilíbrio socioeconômico e de liberdade entre as partes nesta relação.

Tendo em vista o corte proposto para esta pesquisa,na contemporaneidade novas formas de escravidão se apresentam, tal como alertam Karine Gleice Cristova e Rodrigo Goldschmidt (2012, p. 1-2):

A escravidão contemporânea é marcada por fatores como: falsas promessas feitas pelo aliciador, falta de informações e desconhecimento dos direitos pelos trabalhadores e ausência de emprego e condições mínimas para manter a família na região de origem, o que faz com que o trabalhador aceite com mais facilidade a migração para outras regiões distantes em que será explorado.

Os autores afirmam ainda em seu estudo que os trabalhadores escravizados são recrutados em municípios muito carentes, de baixíssimos IDH, e caracterizam-se por serem pessoas de pouco ou nenhum estudo (CRISTOVA, GOLDSCHMIDT, 2012, p. 2). Pode-se apontar que o empregador aproveitase das desvantajosas condições do empregado. Este, normalmente, encontrase em situação de desemprego, em penúria, ávido por uma fonte de renda e que tiverem frustradas as suas expectativas, sonhos e metas. Ao deparar-se com uma proposta de emprego, seja ela qual for, vê-se diante de uma chance irrecusávelde melhoria para sua vida.

Muito similar é a situação de estrangeiros em busca de oportunidades em outros países. Além de enfrentarem a situação de permanência irregular, com possibilidade de deportação, ficam desprovidos de garantias legais para reivindicar seus direitos. Os empregadores, de certa forma, preferem tal condição, pois diminuem os riscos de condenações judiciais uma vez que os imigrantes ilegais não procuram a tutela estatal.

Cristova e Goldschmidt (2012, p. 2) definem ainda a característica principal do escravocrata contemporânea: a propriedade de latifúndios e a posse de modernos e avançados recursos de produção. Ou seja, são eles que detêm o 
controle sobre aquilo que mais anseia o trabalhador: a oportunidade de um trabalho.

Quando se trata da escravidão contemporânea temos o escravocrata como aquele que suprime o status libertatis da pessoa, aquele que sujeita de modo completo o trabalhador ao seu poder discricionário. Tal fato é também conhecido como plagium. Fávero Filho (2010, p. 260) conceitua plagium como:

O exercício ilícito, sobre o trabalhador, de poderes similares àqueles inerentes ao direito de propriedade, restringindo-lhe a liberdade de locomoção através do uso da violência, grave ameaça ou fraude,bem como mediante a retenção de documentos pessoais ou contratuais ou em razão de dívida contraída com o empregador,com frustração de direitos trabalhistas e imposição de trabalhos forçados e em condições degradantes.

Tendo conhecimento sobre a figura do trabalhador escravizado e do escravocrata, pode-se, de modo mais contundente, analisar propriamente o conceito de trabalho escravo contemporâneo.

\subsection{O conceito de trabalho escravo contemporâneo}

Cumpre destacar, primeiramente, que a doutrina brasileira não é unânime quando a conceituação do trabalho escravo contemporâneo, nem mesmo quando a sua nomenclatura. Nesta senda salienta-se:

'Neo-escravidão', 'escravidão branca', 'trabalho forçado', 'trabalho escravo'; 'semiescravidão', 'superexploração do trabalho'; 'forma degradante de trabalho', 'trabalho escravo contemporâneo'; 'trabalho em condições análogas à de escravo', além de outras, são expressões utilizadas para fazer referência àquela modalidade de exploração da força de trabalho humana ocorrente na atualidade, na qual a sua prestação se dá de forma involuntária, e que é advinda de coerção amparada em pretensa existência de dívida, predominantemente ocorrente no âmbito do trabalho rural. (FÁVERO FILHO, 2010, p. 260).

Franco Filho (apud BRITO FILHO, 2004) não concorda com a utilização da expressão "trabalho escravo", pois considera que não deve ser usado um termo com conotação de fato que foi extinto formalmente pela Lei Áurea no Direito Brasileiro desde 1888. Brito Filho explica que a denominação usada no direito penal brasileiro é "trabalho em condições análogas à de escravo", embora 
pelo uso costumeiro haja menção apenas ao "trabalho escravo". O autor explica que deve se ter em mente o efetivo sentido da expressão, porque a escravidão não é admitida no ordenamento jurídico do país, então uma pessoa não pode ser considerada escrava, no máximo ela estará em condições análogas à de escravo (BRITO FILHO, 2004).

Afirma-se, de modo majoritário, que a nomenclatura mais usual, inclusive devido a sua grande veiculação pela mídia, é "trabalho escravo". Neste estudo, entretanto, deparar-se-á com as das expressões citadas pelo professor Fávero Filho. Todas, contudo, rememorando ao mesmo significado.

De acordo com o artigo $2^{\circ}$ da Convenção 29 da Organização Internacional do Trabalho (1930), internalizado no Brasil nos termos do Decreto $\mathbf{n}^{\mathbf{0}} \mathbf{4 1 . 7 2 1}$, de 25 de junho de 1957, "trabalho forçado ou obrigatório é o serviço exigido de um indivíduo mediante ameaças ou pena qualquer e para o qual o indivíduo não se oferece voluntariamente",(grifo nosso).

O Código de Penal Brasileiro (Decreto-Lei no 2.848 , de 7de dezembro de 1940), por sua vez, define o trabalho escravo em seu artigo 149 como sendo aquele que:

\section{Redução a condição análoga à de escravo}

Art. 149. Reduzir alguém a condição análoga à de escravo, quer submetendoo a trabalhos forçados ou a jornada exaustiva, quer sujeitando-o a condições degradantes de trabalho, quer restringindo, por qualquer meio, sua locomoção em razão de dívida contraída com o empregador ou preposto:

Pena - reclusão, de dois a oito anos, e multa, além da pena correspondente à violência.

$\S 1^{\circ}$ Nas mesmas penas incorre quem:

I - cerceia o uso de qualquer meio de transporte por parte do trabalhador, com o fim de retê-lo no local de trabalho;

II - mantém vigilância ostensiva no local de trabalho ou se apodera de documentos ou objetos pessoais do trabalhador, com o fim de retê-lo no local de trabalho.

$\S 2^{\circ}$ A pena é aumentada de metade, se o crime é cometido:

I - contra criança ou adolescente;

II - por motivo de preconceito de raça, cor, etnia, religião ou origem.

Pode-se concluir que ao comparar o texto normativo da OIT e do Código Penal, a norma brasileira é mais abrangente quanto à definição de trabalho escravo. Para o Brasil, portanto, há outras formas de condutas que impõe a condição de escravidão, além daquela que enfatiza a imposição de condições 
de trabalho sem a concordância do trabalhador. Esta definição internacional está, ainda, no contexto jurídico que tutela a autonomia de vontade das partes nas relações jurídicas sem considerar as condições de desequilíbrio social e econômico do trabalhador.

Para o doutrinador trabalhista brasileiro Jairo Lins de Albuquerque SentoSé (2001, p. 27):

[...] trabalho escravo é aquele em que o empregador sujeita o empregado a condições de trabalho degradantes, inclusive quanto ao meio ambiente em que irá realizar sua atividade laboral, submetendo-o, em geral, a constrangimento físico e moral que vai desde a deformação do seu consentimento ao celebrar o vínculo empregatício, passando pela proibição imposta ao obreiro de resilir o vínculo quando bem entender, tudo motivado pelo interesse mesquinho de ampliar os lucros às custas da exploração do trabalhador.

$\mathrm{Na}$ esteira desse conhecimento se posiciona Lívia Mendes Moreira Miraglia (2008, p. 135):

[...] pode-se inferir que o trabalho escravo contemporâneo é aquele que se realiza mediante a redução do trabalhador a simples objeto de lucro do empregador. O obreiro é subjugado, humilhado e submetido a condições de gradantes de trabalho e, em regra, embora não seja elemento essencial do tipo,sem o direito de rescindir o contrato ou de deixar o local de labor a qualquer tempo.

O doutrinador Fávero Filho (2010, p.90) aponta como característica marcante do trabalho escravo contemporâneo o fato de o empregador sujeitar o empregado a condições de trabalho degradantes, constrangendo-o fisicamente e moralmente, de maneira que consiga viciar o seu consentimento na celebração do contrato empregatício e proibi-lo de rescindir voluntariamente o vínculo. Tudo isso, faz o empregador com o único objetivo de ampliar seus lucros à custa da exploração do trabalhador.

Neste sentido afirma o Subprocurador-Geral do Trabalho, professor Luís Antônio Camargo de Melo (2009, p. 3):

O trabalho forçado é aquela situação em que o trabalhador é levado, mediante falsas promessas, de um município para outro, de um Estado para outro da federação, porque naqueles municípios onde ele se encontra não tem 
condições de desenvolvimento, de sobrevivência. Enfim, são municípios de extrema miséria. Nós temos municípios no Piauí e no Maranhão, mas especialmente no Estado do Piauí, diversos municípios já perfeitamente identificados como grandes fornecedores de mão-de-obra para o trabalho forçado, porque são municípios onde as pessoas não têm trabalho, não tem emprego.

Conclui-se que nos termos jurídicos é certo defender que o trabalho escravo é marcado por uma dominação velada do empregador sobre o empregado. Este último possui sua liberdade física e moral suprimida. Avaliando o contexto histórico da Lei Áurea brasileira (Lei Imperial n. ${ }^{\circ} 3.353$, sancionada em 13 de maio de1888) hoje, a escravidão não advém de um contrato de compra e venda de seres humanos, da limitação do direito de ir e vir, ou da ausência de manifestação da vontade. Na atualidade constata-se de falsas promessas por parte do empregador que resultam de ilegais e inconstitucionais subordinações a condições pessoais, de ambiente de trabalho, de isolamento geográfico, de dependência econômica e moral.

A escravidão contemporânea no Brasil faz, sem dúvida, mais vítimas no meio rural. Isso se dá pelo fato de que, longe dos holofotes das grandes cidades, a prática se torna velada e desconhecida pelas autoridades. Em meio as fazendas distantes de grandes centros urbanos mais fácil se torna esconder o trabalhador em condição análoga a de escravo e também mais persuasiva se torna a coação. Muitas vezes, quando se trata de trabalhadores estrangeiros a maioria deles não sabem nem em qual localidade geográfica se encontram, o que dificulta a fuga.

Tendo em vista atingir o tema central deste estudo, qual seja, o trabalho escravo urbano de bolivianos nas oficinas de costura da grande São Paulo necessário se faz definir o conceito de trabalho escravo contemporâneo urbano.

\subsection{O conceito de trabalho escravo contemporâneo urbano}

Com relação ao trabalho escravo urbano, Wilson Ramos Filho (2008, p.282), afirma em seu estudo que este se divide em duas espécies: i) aquele prestado nas cidades em condições análogas à de escravo sem suporte contratual válido; e, ii) outro com suporte contratual válido, também denominado neoescravidão". Na primeira hipótese, um dos exemplos mais frequentes são os trabalhadores imigrantes nas cidades, que por reconhecerem sua condição de clandestinos ou ilegais se sujeitam à exploração, muitas vezes abdicando do 
direito inalienável de ir e vir. Quanto ao trabalho com suporte contratual válido,geralmente não implica restrição do direito de ir evir, "mas 'tão-somente' se impõe trabalho degradante ou trabalho prestado em jornadas exaustivas".

O tema também foi objeto de estudo da autora MaristelaCoppini (2012, p. 232):

Quanto ao trabalho escravo urbano, as grandes empresas varejistas estão presentes nessa corrente de exploração, para produzir o ritmo alucinante da moda para consumo rápido; terceirizar a produção é também uma forma de fugir das responsabilidades trabalhistas. Geralmente o sweat system se aproveita da condição de imigrante ilegal do cativo. A escravidão contemporânea torna-se mais fácil de ser praticada, pois não mais se restringe às etnias, mas à força de trabalho disponível, se atém à brevidade da relação uma vez que a propriedade não é aceita no ordenamento jurídico e o valor da mão de obra é baixíssimo.

A realidade é que o trabalho urbano e o rural possuem uma vinculação. Isso porque a penúria do campo, que expulsa trabalhadores de suas terras, é um dos maiores fatores do crescimento desordenado das cidades. Estes ao se deslocarem dos interiores do Brasil e mesmo aqueles que atravessam fronteiras, para se alocarem nos grandes centros urbanos, são aqueles que, meses depois se submetem a condições análogas a de escravos. Vera Lúcia Carlos mostra como se dá o processo de submissão do trabalhador no meio urbano:

Nos grandes centros urbanos, a violação da dignidade da pessoa humana e a prestação de serviços em condições análogas à de escravo também se faz presente, trata-se da exploração da mão-de-obra dos trabalhadores latinos, geralmente bolivianos e paraguaios que são aliciados em seus países de origem e ingressam irregularmente no Brasil com promessas de bom salário e passam a trabalhar, sem qualquer reconhecimento do seu trabalho, para proprietários de oficinas de costuras onde residem em condições degradantes, recebendo alimentação insuficiente e ao final do mês, após o pagamento das despesas que lhes são apresentadas pela moradia e alimentação, nada lhes resta, a não ser continuar a trabalhar sob a ameaça de expulsão do país, por meio de denúncias às autoridades competentes (CARLOS, 2006, p. 267).

Não é diferente o trabalho nas confecções de roupas na cidade de São Paulo com a mão de obra boliviana, conforme destaca a análise de Flávio Azevedo: 
Ao longo das entrevistas realizadas para a pesquisa, pudemos detectar que a grande maioria chega ao território com um contrato de trabalho verbal, onde foi prometido trabalho com moradia e alimentação. Outras vezes, que os gastos da viagem forma garantidos pelo empregador, iniciando-se assim um processo de endividamento e dependência do empregador, muito semelhante ao que ocorre no âmbito rural, que cobriu os custos da viagem e da documentação; forneceu trabalho; moradia; e alimentação. Destarte, verifica-se uma relação de fidelidade e de dependência do empregado ao empregador muito forte, que perdura muitas vezes por meses a fio ou até mesmo anos. Neste contexto, de fidelidade, de dependência e quiçá de "servidão" é que se estabelecem às relações de emprego da comunidade boliviana na cidade de São Paulo. (AZEVEDO, 2005, p. 30)

Sendo assim é possível afirmar que o trabalho escravo urbano em análise é aquele realizado em meio a condições degradantes de trabalho, com jornadas exaustivas e em desrespeito a condições mínimas que garantam um ambiente se trabalho sadio. Normalmente não está vinculada a restrição de liberdade (ir e vir), pois o trabalhador vai até a sua casa ou pensão cedida pelo próprio empregador para passar o curto período de descanso noturno. Além disso, muitas vezes está ligado a dívidas contraídas com o empregador ou aliciador, que limitam a sua desvinculação do trabalho.

O que tem prevalecido nos posicionamentos dos Tribunais Pátrios é uma interpretação restritiva do artigo 149 do Código Penal Brasileiro e do artigo $2^{\circ}$ da Convenção 29 da OIT. Na maioria das vezes a tipificação deste trabalho vem associada a restrição de liberdade do trabalhador:

\begin{abstract}
ANÁLOGAÀ DE ESCRAVO(ART. 149/CP). INEXISTÊNCIADE PROVADA MATERIALIDADE OU DAAUTORIA. REJEITADAA PRELIMINAR DE INÉPCIADA DENÚNCIA. APELO DADEFESA PROVIDO. 1. A denúncia, a teor do art. 41 do Código de Processo Penal, descreve de forma satisfatória e individualizada os fatos imputados aos acusados. Preliminar de inépcia que se rejeita. 2. Para a configuração de redução de trabalhador à condição análoga à de escravo faz-se necessária a completa sujeição da pessoa que tenha relação de trabalho ao poder do sujeito ativo do crime, não bastando a submissão do trabalhador a condições precárias de acomodações. Tal situação é censurável,mas não configura o crime do art. 149 do Código Penal. 3. Recurso provido. (TRF-1 - ACR: 10340 PA 2004.39.00.010340-5, Relator: JUIZ MARCUS VINICIUS REIS BASTOS (CONV.), Data de Julgamento: 02/ 08/2011, QUARTA TURMA, Data de Publicação: e-DJF1 p.162 de 16/09/ 2011, grifo nosso)
\end{abstract}


PENALE PROCESSO PENAL. CRIME PREVISTONOART. 149 DOCPNÃO CONFIGURADO. INEXISTÊNCIA DE RESTRIÇÃO À LIBERDADE DOS EMPREGADOS. CRIME PREVISTO NO $\S 4^{\circ}$ DO ART. 297 DO CP IGUALMENTE NÃO CONFIGURADO. AUSÊNCIA DE DESCRIÇÃO ADEQUADADACONDUTADADENÚNCIAE DE DOLOESPECÍFICO DO AGENTE PARA O CRIME DE FALSO. I O fato do salário dos empregados ser pagos na forma de crédito no comércio local, não tem, por si só, o condão de transformar essa situação em condição análoga à de escravo, sendo imprescindível que essa característica funcione como fator de restrição à liberdade deles. Condição não provada. II A permanência de duas pessoas em situação de miséria em área pertencente à fazenda do acusado não decorre de qualquer tipo de relação de emprego, mas de mero ato de liberalidade com intuito caritativo, relacionado à situação econômica e socialmente precária dos mesmos, não podendo ser atribuída àquele a responsabilidade pela respectiva manutenção. III A denúncia não especifica os empregados em relação aos quais teria havido omissão do acusado em inserir informações obrigatórias nas respectivas CTPS, nem tampouco descreve adequadamente a conduta dolosa do agente. IV A conduta de quem simplesmente deixa de assinar a CTPS do empregado não configura a prática do crime previsto no $\S$ $4^{\circ}$ do art. 297 do CP, sendo indispensável a demonstração do dolo do agente para a prática do crime de falso, o que não restou configurado no presente caso. V Recurso do MPF não provido. Recurso da defesa provido para absolver o acusado da prática do tipo previsto no $\S 4^{\circ}$ do art. 297 do CP.(TRF2 -ACR: 200451080002794 RJ 2004.51.08.000279-4, Relator: Desembargador Federal ABEL GOMES, Data de Julgamento: 10/02/2010, PRIMEIRATURMA ESPECIALIZADA, Data de Publicação: E-DJF2R - Data::27/04/2010 Página::83/84, grifo nosso)

PENAL. PROCESSO PENAL. ART. 149 DO CP. REDUÇÃOACONDIÇÃO ANÁLOGA À DE ESCRAVO. SUPRESSÃO DA VONTADE DA VÍTIMA NÃO COMPROVADA. I - O art. 149 do CP enumera condutas alternativas e não cumulativas. Para que se configure o referido tipo penal, "é imprescindível a supressão da vontade da vítima". II - Não havendo provas suficientes para condenação, mantém-se a sentença absolutória. II - Apelação desprovida.(TRF-1 - ACR: 2456 TO 0002456-17.2004.4.01.4300, Relator: DESEMBARGADOR FEDERAL CÂNDIDO RIBEIRO, Data de Julgamento: 18/02/2013, TERCEIRA TURMA, Data de Publicação: e-DJF1 p.568 de 08/03/ 2013, grifo nosso)

O trabalho escravo contemporâneo urbano, tal qual aqueles relembrados pela literatura, ofende princípio da dignidade da pessoa humana, em especial 
quando o trabalhador é submetido a jornadas exaustivas e diárias de trabalho além do legalmente permitido, ambiente de trabalho sem condições mínimas de higiene.

Além das implicações de reparações materiais e morais no âmbito trabalhista,em situações tais, é possível qualificar como trabalho escravo nos termos do artigo 149 do Código Penal Brasileiro.

PENAL. PROCESSUAL PENAL. RECURSO CRIMINAL. REDUÇÃO À CONDIÇÃO ANÁLOGAÀ DE ESCRAVO.ART. 149 DO CP. REJEIÇÃO DA DENÚNCIA. PROVA DA MATERIALIDADE. INDÍCIOS DE AUTORIA. REQUISITOS DO ART. 41 DO CPP. PREENCHIMENTO. RECEBIMENTO. RECURSO PROVIDO. 1. Diante dos fatos narrados na denúncia - submissão de um grupo de trabalhadores a condições degradantes de trabalho, em alojamento precário, sem qualquer instalação sanitária, água potável, equipamentos de proteção individual ou local adequado para armazenamento de alimentos etc - existem indícios veementes da prática do delito previsto no art. 149 do Código Penal Brasileiro. 2. O tipo penal do art. 149 do Código Penal, em sua nova redação dada pela Lei 10.803/2003, prevê quatro condutas alternativas (Reduzir alguém a condição análoga à de escravo, quer submetendo-o a trabalhos forçados ou a jornada exaustiva, quer sujeitando-o a condições degradantes de trabalho, quer restringindo, por qualquer meio, sua locomoção em razão de dívida contraída com o empregador ou preposto), não sendo mais necessária a prova do cárcere privado e privação de liberdade para sua configuração. 3. Considerando que a denúncia se apresenta de acordo com os requisitos legais, previstos no art. 41 do CPP, expondo os fatos criminosos com todas as suas circunstâncias, deve ser recebida. 4. Recurso em sentido estrito provido. (TRF-1 - RSE: 17239 TO 0017239-04.2010.4.01.4300, Relator: DESEMBARGADOR FEDERAL CARLOS OLAVO, Data de Julgamento: 26/03/2012, TERCEIRA TURMA, Data de Publicação: e-DJF1 p.109 de 03/ 04/2012, grifo nosso)

O Subprocurador-Geral do Trabalho e professor de Direito do Trabalho do Instituto de Ensino Superior de Brasília, Luís Antônio Camargo de Melo, sobre o tema já se posicionou claramente:

Uma certeza: há uma resistência muito grande em relação a essas condições degradantes, eu não tenho dúvida. Se há trabalho forçado, se há condição degradante, se há jornada exaustiva, se há servidão por dívida, então nós estamos diante do crime capitulado no art. 149 do Código Penal, que é o 
crime de reduzir alguém à condição análoga à de escravo. (CAMARGO DE MELO, 2009, p. 6).

Posição semelhante tem o autor quanto a interpretação restrita do artigo $2^{\circ}$ da Convenção 29 da OIT, ao considerar que apenas se trata de trabalho forçado aquele que advém de um não consentimento em realizar determinadas funções. Desta forma está-se excluindo o trabalhador que consentiu com o trabalho em virtude de não ter conhecimento de que se tratava, em verdade, de um trabalho em condições degradantes.

Em um primeiro momento, a leitura, especialmente da parte final do artigo $2^{\circ}$ da Convenção 29, pode trazer uma idéia equivocada de que aquele trabalhador que se ofereceu espontaneamente para a prestação de serviço e, ao final, acabou explorado, não estaria protegido. Ledo engano. O próprio Comitê de Peritos - está aqui o Ministro Lélio, um dos integrantes do Comitê de Peritos da OIT - já sinalizou, já apontou no sentido de que, quando o trabalhador, ainda que ele vá de espontânea vontade, mas quando ele é vítima de uma fraude, é vítima de um engano, quando ele é enganado, e isso é comum, é cotidiano no Brasil, nos casos em que nós observamos do chamado "trabalho escravo contemporâneo", ainda assim a Convenção 29 é o marco legal internacional para a proteção desse trabalhador, ou seja, se o trabalhador se oferece de livre e espontânea vontade, mas a oferta de trabalho, na verdade, é uma fraude, esse trabalhador está sendo enganado, incide, como item de proteção, a Convenção 29 da Organização Internacional do Trabalho. (CAMARGO DE MELO, 2009, p. 02)

É preciso buscar outras interpretações em face da sociedade complexa que atualmente se apresenta. Há novos riscos dos quais o trabalho precisa ser protegido, especialmente, quando for demonstrada a boa-fé e as condições de desigualdade em face das dificuldades sociais e econômicas do país ou do Estado de origem destes trabalhadores.

\section{O TRABALHO DE BOLIVIANOS NAS OFICINAS DE COSTURA DE SÃO PAULO E A ORDEM JURÍDICA BRASILEIRA DE PROTEÇÃO AO TRABALHO HUMANO}

São frequentes as notícias a cerca da descoberta de mais uma empresa têxtil responsável pela exploração irregular de mão-de-obra do trabalhador, 
evidenciando a ainda existência do trabalho escravo contemporâneo ${ }^{1}$. Um dos exemplos são os relatos de trabalhos em São Paulo, nas pequenas tecelagens do bairro Brás.O tema foi matéria do programa de TV Profissão Repórter, da Rede de TV Brasileira Globo, em 09 de Abril de 2013. ${ }^{2}$ A matéria veiculada abordou a trajetória de bolivianos, ainda em La Paz, onde são aliciados para trabalhar no Brasil. Ao chegar trabalham em desacordo com a legislação brasileira e submetidos a condições desumanas no ambiente do trabalho. Tais constatações estão comprovadas pela fiscalização do Ministério do Trabalho, Ministérios Público Federal e por membros da Comissão Parlamentar de Inquérito-CPI.

Tudo começa com a oferta de trabalho publicada sem qualquer pudor em diversos murais espalhados pelo centro de La Paz. A passagem paga evidencia uma dívida que começa já na viagem. Sem abrigo, comida ou água, centenas de trabalhadores bolivianos passam a madrugada na fila, à espera de um visto para entrar no Brasil:

Embora suas motivações sejam primordialmente econômicas, o fenômeno da diáspora boliviana não deve ser visto apenas como um deslocamento populacional de pessoas de uma região pobre para outra mais desenvolvida em busca de ascensão social ou se restringir ao tema das remessas. Ao contrário, direitos políticos, civis e sociais dos migrantes, questões identitárias, conflitos interculturais e transformações nas relações familiares e de gênero merecem igual atenção. (NÓBREGA, 2009, p. 3)

Importa destacar que tal presença não é um fenômeno novo, pois pode ser constatada já na década de 90 do século XX. Segundo Rosana Baeninger em 1990 o Brasil contava com 15.694 mil emigrantes. Em 2000, entretanto, a população estrangeira brasileira já contava com 20.388 bolivianos. (BANINGER, 2012, p.13).

Pequenas fábricas e oficinas clandestinas utilizam-se do trabalho irregular, que aqui ingressam com dívidas já acumuladasem razão de seu transporte e de sua moradia. Esta, na maioria das vezes, como mostrou o programa Globo Repórter, confunde-se com o próprio ambiente de trabalho. Os trabalhadores subordinam-se a jornadas de trabalho exaustivas, que chegam a 16 horas diárias,

\footnotetext{
${ }^{1}$ Estrangeiros resgatados de escravidão no Brasil são 'ponta de iceberg'. Bolivianos, paraguaios e chineses estão entre imigrantes que vieram ao país atrás de oportunidades mas acabaram vítimas de formas contemporâneas de escravidão. (ESTRANGEIROS ... 2013).

${ }^{2}$ Disponível em: <www.youtube.com/watch?v=8Q_krV18R4g>
} 
bem como a salários irrisórios, muitas vezes até menos da metade de um salário mínimo brasileiros mensal (PROFISSÃO REPÓRTER, 2013).

A autora Camila Lins Rossi (2005, p. 23) descreve o trabalho das oficinas de costura:

As oficinas, segundo contam os imigrantes, funcionam em porões ou em locais escondidos, porque a maior parte delas é ilegal e não tem permissão para funcionar regularmente. Por isso, para que os vizinhos não percebam, para não levantar suspeitas da polícia, para evitar que a confecção seja descoberta e denunciada, as máquinas funcionam em lugares fechados, onde o ar não circula e a luz do dia não entra. Para camuflar o barulho dos motores, musica boliviana toca o tempo todo. De acordo com os relatos, os cômodos são divididos por paredes de compensado, uma estratégia para que os trabalhadores fiquem virados para a parede, sem condições de ver e relacionarse com o companheiro que trabalha ao lado. Isso e também a música alta evitam que os trabalhadores conversem e discutam sua situação, que busquem alternativas para reivindicar melhores condições.

Em seu estudo a autora ainda relata os meios de privação de liberdade exercidos pelo empregador. Afirma que, em muitas ocasiões de ausência do empregador o mesmo tranca a porta de saída pelo lado de fora para que os trabalhadores bolivianos não deixem o serviço. Alerta ainda que em diversas oficinas são encontradas fiações expostas que trazem sério risco de explosão e choques. Tais pareceres evidenciam a precarização dos ambientes de trabalho. (ROSSI, 2005, p. 23)

Quanto à alimentação e moradia dos trabalhadores bolivianos, aponta o estudo de Rossi (2005, p. 23-24):

Quanto à alimentação dos imigrantes, ela é fornecida pelo dono da oficina. Mas as três refeições diárias - café da manhã, almoço e jantar, com duração cerca de 20 minutos cada uma - tampouco são uma cortesia do patrão. $\mathrm{O}$ valor é descontado do saldo a receber, assim como água, luz e moradia. Este último item, aliás, também é absolutamente precário. Os imigrantes vivem nas próprias oficinas e, assim, o local de trabalho e o local de moradia são literalmente o mesmo. Quando param de trabalhar, por volta da meia-noite, 1 hora, os trabalhadores estendem os colchonetes no chão e dormem, ali mesmo, ao lado das máquinas. Quando levantam, ao redor das 5 horas, enrolam os colchonetes, os colocam em um canto e recomeçam o trabalho. 
Observa-se que, de modo geral, diversas situações acima relatadas estão expressamente proibidas pela Constituição Federal Brasileira ao garantir no Art. $7^{\circ}$ direitos dos trabalhadores urbanos e rurais, além de outros que visem à melhoria de sua condição social: i)Art. $7^{\circ}$, VII que garante a todos que trabalham no Brasil salário nunca inferior ao mínimo, mesmo para aqueles que recebem remuneração variável, como é o caso dos trabalhadores bolivianos; ii)Art. $7^{\circ}$, IX, dispõe sobre trabalho noturno que gera direito a adicional; iii)Art. $7^{\circ}, \mathrm{XV}$, trata do direito a repouso semanal remunerado; iv)Art. $7^{\circ}$, XIII e XVI, estabelecem direito a limite para jornada de trabalho com remuneração diferenciada para tempo superior a oito horas diárias e quarenta e quatro semanais; v)Art. $7^{\circ}$, XXII, prevê a redução dos riscos inerentes ao trabalho, por meio de normas de saúde, higiene e segurança; vi)Art.,XXIII, assegura direito a adicionais em havendo prática de trabalho em locais insalubres.

Todos os direitos mencionados são indisponíveis e invioláveis e albergam todos os trabalhadores que trabalham no território nacional, sendo eles nacionais ou estrangeiros. Relativamente o tema, comenta a autora Lourdes Cortes (2012) sobre o posicionamento do Tribunal Superior do Trabalho:

Ao trabalhar no país, o estrangeiro passa a ter os mesmos direitos trabalhistas de um empregado natural do Brasil, como $13^{\circ}$ salário, FGTS e férias de 30 dias, entre outros. Também vale destacar a jornada padrão de oito horas diárias ou 44 por semana, com um dia de folga, preferencialmente aos domingos. São inúmeras as decisões proferidas pela Justiça do Trabalho, nas quais estrangeiros conseguem o reconhecimento de direitos decorrentes da relação de emprego.

No mesmo sentido o posicionamento do Tribunal Regional do Trabalho da $4^{\text {a }}$ região:

VÍNCULO DE EMPREGO. VALIDADE DO CONTRATO DE TRABALHO. ESTRANGEIRO EM SITUAÇÃO IRREGULAR NO PAÍS.O art. 359 da CLT impõe ao empregador a obrigação de observar, quando da contratação de empregado estrangeiro, a regularidade de sua situação no território nacional. Se assim não o faz, assume o risco da omissão. No caso dos autos, ainda que se pudesse entender que a permanência irregular do reclamante no Brasil impediria o exercício de atividade remunerada, tal como dispõe o art. 98 da Lei $\mathrm{n}^{\circ} 6.815 / 80$, não se pode admitir tenha essa circunstância o poder de retirar daquele que aliena a sua força de trabalho o direito àquilo a que faz jus, sob pena de afronta à Constituição Federal, que, além de assegurar 
como pilar de todo o ordenamento jurídico o respeito à dignidade da pessoa humana e estabelecer como fundamento do Estado Democrático de Direito o valor social do trabalho, na forma do art. $1^{\circ}$, III e IV, consagra o princípio da isonomia. Entendimento manifestado pelo TST no processo $n^{\circ}$ TST-RR750.094/01.2. Recurso da reclamada a que se nega provimento. (TRT-4, Relator: MARÇAL HENRI DOS SANTOS FIGUEIREDO, Data de Julgamento: 17/06/

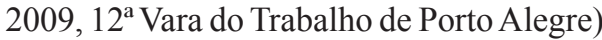

Nos termos relatados e em face das análises judiciais pode-se afirmar que os imigrantes bolivianos são submetidos a trabalhos análogos ao de escravo. Tal conduta é tipificada no artigo 149 do Código Penal Brasileiro:

Art. 149. Reduzir alguém a condição análoga à de escravo, quer submetendoo a trabalhos forçados ou a jornada exaustiva, quer sujeitando-o a condições degradantes de trabalho, quer restringindo, por qualquer meio, sua locomoção em razão de dívida contraída com o empregador ou preposto:

Pena - reclusão, de dois a oito anos, e multa, além da pena correspondente à violência.

A proteção desses trabalhadores é fundamental para que possa exercer de modo digno o trabalho no Brasil.Entretanto, para que tais condutas sejam erradicadas, faz-se necessária responsabilização trabalhista material e moral das empresas privadas, desde os aliciadores, seguindo para as oficinas e daquelas que comercializam as roupas que, em última instância, em cadeia patrocinam essas atrocidades.

Não responsabilizá-las é, em verdade, não punir um crime que deveria ser qualificado como hediondo. E o mais grave destas denúncias e da impunidade,é que colocam o Brasil na condição de conivência em momento que se comprometeu com a OIT por meio de uma a Agenda Nacional de Trabalho Decente.

Segundo o Ministério Público do Trabalho o ganho de mercado ocorre à custa de recursos pouco éticos, como exploração de mão de obra irregular. Tal conduta foi apelidada de dumping social, ou seja, sonegação de direitos trabalhistas para aumentar o lucro e promover concorrência desleal (ALMEIDA, 2013, p.20)

Em pleno século 21, no entanto, dados da Divisão de Fiscalização para Erradicação do Trabalho Escravo do Ministério do Trabalho e Emprego (MTE) mostram que mais de 43 mil trabalhadores foram resgatados entre 1995 e 2012 
em 3.353 estabelecimentos inspecionados durante as operações de fiscalização para erradicação do trabalho escravo moderno. O trabalho forçado, a servidão por dívida, a jornada exaustiva ou trabalho degradante, apesar de serem crimes tipificados no artigo 149 do Código Penal, ainda são uma realidade no campo e nas cidades brasileiras (ALMEIDA, 2013, p.14).

O trabalho escravo no Brasil também é objeto de investigação pelo parlamento conforme Ato da Presidência de 27/03/2012 com a seguinte ementa: "Constitui Comissão Parlamentar de Inquérito destinada a investigar a exploração do trabalho escravo ou análogo ao de escravo, em atividades rurais e urbanas, de todo o território nacional." A importância desta atividade parlamentar é que poderá concluir pela elaboração de projeto de lei contendo normas mais específicas e claras para punir formas de trabalho escravo e, especialmente, poderia estabelecer uma cadeia de responsabilização de pessoas físicas e jurídicas que participassem direta ou indireta na cadeia produtiva e de comercialização. Mas, infelizmente, noticia o sitio ${ }^{3}$ da Câmara dos Deputados, que a CPI está encerrada. Assim, mais uma vez, o Brasil perde oportunidade para atuar de forma eficiente no dever de promover a valorização do trabalho humano, tal como está no caput do Art. 170 da CF/88.

Resta a alternativa da Proposta de Emenda Constitucional-PEC n ${ }^{\circ}$ 438/ 01 (que volta a tramitar como PEC 57A/1999), aprovada na Câmara dos Deputados e em trâmite no Senado $\mathrm{Federal}^{4}$, propondo alterar o artigo 243 da Constituição Federal e prevê a expropriação (desapossar alguém de sua propriedade, sem indenização, mas obedecido o devido processo legal) de imóveis rurais e urbanos quando constatado que neles existe trabalho análogo ao de escravo.A aprovação desta proposta será fundamental para a erradicação do trabalho escravo no Brasil uma vez que está dirigidaao setor econômico e a sanção pode ser considerada a mais grave para um regime capitalista e uma ordem jurídica que assegura o direito à propriedade privada.

Se for aprovada a PEC em análise, o Estado brasileiro poderá resgatar a imagem de conivência com um crime inaceitável manchando o caminho de um Estado que em seu texto constitucional (Art. $1^{\circ}$, III e IV) optou por um

\footnotetext{
${ }^{3}$ A Comissão Parlamentar de Inquérito do Trabalho Escravo encerra as atividades sem relatório final. O presidente da CPI acusa deputados da bancada ruralista de tentarem usar o colegiado para flexibilizar a legislação trabalhista. (TV Câmara 25/03/2013, 20:00). Informações no site <www2.camara.leg.br/ legin/int/atopre_sn/2012/atodapresidencia-55302-27-marco-2012-613155-norma-cd-presi.html>. ${ }^{4}$ Remessa ao Senado Federal através do Of. $n^{\circ}$ 331/12/PS-GSE. Informações no site <http:// www.camara.gov.br/proposicoesWeb/fichadetramitacao?idProposicao=36162>.
}

REVISTA DO DIREITO PÚBLICO, Londrina, v.8, n.3, p.77-102, set./dez.2013 
desenvolvimento econômico sustentável. Este paradigmapermite promover e proteger a dignidade da pessoal humana, os valores sociais do trabalho e da livre iniciativa quando esta cumpre a sua função social.

\section{CONSIDERAÇÕES FINAIS}

Ao analisar o conceito de trabalho decente definido pela Organização Internacional do Trabalho (1932), da Declaração Relativa aos Direitos e Princípios Fundamentais no Trabalho (1998) e da atual legislação brasileira tuteladora das relações do trabalho, pode-se afirmar que o Brasil está conforme as diretrizes internacionais. Ou seja, há condições jurídicas para este trabalho, pois há normas que tratam de direitos no trabalho, da promoção do emprego produtivo e de qualidade, da proteção social e o fortalecimento do diálogo social, da liberdade sindical, do direito de negociação coletiva; da eliminação de todas as formas de trabalho forçado; da abolição efetiva do trabalho infantil e da eliminação de todas as formas de discriminação em matéria de emprego e ocupação.

Estas conquistas jurídicas permitem estabelecer paradigma para julgar, em face de uma realidade, o quão distante está o "mundo" do Direito do "mundo" das relações humanas. Neste sentido a pesquisa no Projeto Diálogos Jurídicos e Filosóficos Sobre a Intervenção do Estado no domínio Econômico: Ética Empresarial À Luz do Regime Econômico Constitucional (2012-2013), desenvolvido na Universidade Estadual de Direito de Londrina, em uma de suas etapas, analisou a questão do trabalho dos bolivianos nas oficinas de costura em São Paulo (bairro do Brás). Conclui que o trabalho realizado é trabalho indecente. Infelizmente, tem-se inúmeras condutas contrárias a todos os documentos jurídicos acima mencionados e que são paradigmas de conquistas das lutas sociais no trabalho ao longo de séculos, inclusive no Brasil e na Bolívia.

Esta conduta antijurídica não pode mais ser limitada ao que a OIT define como trabalho escravo, ou seja, "trabalho forçado ou obrigatório é o serviço exigido de um indivíduo mediante ameaças ou pena qualquer e para o qual o indivíduo não se oferece voluntariamente”. Constatou-se que embora alguns bolivianos estivessem nas oficinas por decisão própria, as condições péssimas do ambiente de trabalho, a baixa remuneração, o excesso diário de jornada, permite defender que é um regime comparado aoda escravidão conforme descreve a conduta crime do Código Penal Brasileiro. 
Apesar de todas as normas jurídicas nacionais e internacionais estas condutas escravagistas,condenáveis sob qualquer critério de análise,persistem. Portanto, um dos caminhos para diminuir e erradicar tais condutas seja impor, cumulativamente, aos criminosos: i) pena de reclusão; ii) indenizações trabalhistas materiais e morais; iii) punir aqueles que integram a cadeia de aliciamento,produção e de comercialização, pois obtiveram proveito econômico; e, talvez, a mais eficiente punição:iv) expropriação da propriedade privada rural ou urbana conforme propõe a PEC 438/01, em trâmite no Senado Brasileiro.

A imigração de trabalhadores bolivianos para São Paulo tem entre outras importantes causas, as perspectivas desfavoráveis nos âmbitos econômicos e de acesso a direitos sociais vividos na Bolívia. Infelizmente, as promessas da nova constituição boliviana ainda não se realizaram. Mas, tal constatação, não justifica a desumanidade que está ocorrendo no Brasil.

É preciso uma ação conjunta para enfrentar esta dívida social. Os Estados brasileiro e boliviano, mercado e sociedade civil devem se unir para abolir esta nova forma de escravidão que depõem contra o discurso de protagonismo no trajeto do desenvolvimento sustentável.

\section{REFERÊNCIAS}

AGENDA. Agenda Nacional de Trabalho Decente. Brasília, 2006. Disponível em: <http://www3.mte.gov.br>. Acesso em: 20 ago. 2013.

\section{ALMEIDA, Rafael. Um problema no Brasil contemporâneo: um} flagrante de trabalho escravo muda paradigma do setor têxtil. Revista do Ministério Público do Trabalho, ano I, n. 1, 2013.

\section{AZEVEDO, Flávio Antonio Gomes de. A presença de trabalho forçado urbano na cidade de São Paulo: Brasil/Bolívia. 2005. Dissertação (Mestrado) - USP, São Paulo.}

\section{BAENINGER, Rosana. O Brasil na rota das migrações latino-} americanas. In: . Imigração Boliviana no Brasil. Campinas:

Núcleo de Estudos de População-Nepo/Unicamp; Fapesp; CNPq; Unfpa, 2012. p. 9-18. 
BOLIVIA. Constitución Politica del Estado. 2007. Aprobada en grande sobre la base de informes de mayorías. Magna Asamblea Constituyente. Bolivia, 2007.

BRITO FILHO, José Cláudio Monteiro de. Trabalho decente: análise jurídica da exploração do trabalho - trabalho forçado e outras formas de trabalho indigno. São Paulo: LTr, 2004.

CAMARGO DE MELO, Luís Antônio. Trabalho escravo contemporâneo. Revista do TST, Brasília, v. 75, n. 1, jan/mar. 2009.

CARLOS, Vera Lúcia. Estratégia de atuação do Ministério Público do Trabalho no combate ao trabalho escravo urbano. In: VELLOSO, Gabriel; FAVA, Marcos Neves (Org.). Trabalho escravo contemporâneo: o desafio de superar a negação. São Paulo: LTr, 2006.

COPPINI, Maristela. Ações legais no combate ao Trabalho Escravo e seus reflexos jurídicos e sociais. Revista do Curso de Direito da Faculdade de Humanidades e Direito, São Paulo, v. 9, n. 9, 2012.

CORTES, Lourdes. Trabalhador estrangeiro no Brasil. 2012. Disponível em: $<$ http://www.tst.jus.br/home/-/asset_publisher/nD3Q/content/otrabalhador-estrangeiro-no-brasil>. Acesso em: 23 ago. 2013.

CRISTOVA, Karine Gleice; GOLDSCHMIDT, Rodrigo. O Trabalho Escravo Contemporâneo no Brasil. In: SIMPÓSIO INTERNACIONAL DE DIREITO: dimensões materiais e eficácias dos direitos fundamentais, 3., 2012, Chapecó. Anais eletrônicos... Chapecó: Unoesc, 2012.

ESTRANGEIROS resgatados de escravidão no Brasil são 'ponta de iceberg’. Globo.com, 13 maio 2013. Disponível em:<http://g1.globo.com/ brasil/noticia/2013/ 05/estrangeiros-resgatados-de-escravidao-no-brasil-saoponta-de-iceberg.html>. Acesso em: 20 ago. 2013.

FÁVERO FILHO, Nicanor. Trabalho Escravo: Vilipêndio à Dignidade Humana. In: PIOVESAN, Flávia; VAZ DE CARVALHO, Luciana Paula. 
Direitos Humanos e Direito do Trabalho. São Paulo: Atlas, 2010.

MIRAGLIA, Lívia Mendes Moreira. Trabalho Escravo Contemporâneo: conceituação à luz do princípio da dignidade da pessoa humana. Belo Horizonte: 2008. Dissertação (Mestrado) - Pontifícia Universidade Católica de Minas Gerais, Belo Horizonte.

NÓBREGA, Ricardo. Migração e globalização popular: trabalhadores bolivianos na pequena indústria têxtil de São Paulo. In: ENCONTRO NACIONAL SOBRE MIGRAÇÕES, 6., 2009, Belo Horizonte. Anais... Belo Horizonte: CEDEPLAR, 2009. p. 1-24.

ORGANIZAÇÃO INTERNACIONAL DO TRABALHO. Convenção (29) sobre o trabalho forçado ou obrigatório. 1930. Disponível em: http:// www.oit.org.br. Consulta em: 22 de Agosto de 2013.

ORGANIZAÇÃO INTERNACIONAL DO TRABALHO. O que é Trabalho Decente. Disponível em: <www.oitbrasil.org.br/content/oque-e-trabalho-decente>. Acesso em: 20 ago. 2013.

PROFISSÃO REPÓRTER. O caminho da exploração dos trabalhadores bolivianos. São Paulo, Globo, 9 abr. 2013. Programa de TV.

PROGRAMA DAS NAÇÕES UNIDAS PELO DESENVOLVIMENTO. Ranking IDH Global 2012. Disponível em:<http://www.pnud.org.br/atlas/ ranking/ Ranking-IDH-Global-2012.aspx >. Acesso em: 8 maio 2013.

RAMOS FILHO, Wilson. Trabalho degradante e jornadas exaustivas: crime e castigo nas relações de trabalho neo-escravistas. Revista do Tribunal Regional do Trabalho da $9^{a}$ Região, n. 61, p. 269-298, jul.-dez. 2008.

ROSSI, Camila Lins. Nas costuras do trabalho escravo. 2005. 49 p. Trabalho de Conclusão de Curso (Graduação em Jornalismo e Editoração) Escola de Comunicações e Artes, Universidade de São Paulo, São Paulo, 2005. 
SENTO-SÉ. Jairo Lins de Albuquerque. Trabalho escravo no Brasil. São Paulo: LTr, 2001.

Artigo recebido em: 02/10/2013 Aprovado para publicação em: 18/11/2013

Como citar: MARTINS, Lara Caxico. KEMPFER, Marlene. Trabalho escravo urbano contemporâneo: o trabalho de bolivianos nas oficinas de costura em São Paulo. Revista do Direito Público, Londrina, v.8, n.3, p.77102, set./dez. 2013. DOI: 10.5433/1980-511X. 2013v8n3p77. 